\title{
Air Jet Erosion Wear Behaviour of Al6061-Carbon Fibre Rod Composites
}

\author{
Ramesh Chinnakurli Suryanarayana ${ }^{1)^{*}}$, Adarsha Hiriyannaiah ${ }^{2)}$, Prajwal Rangappa Gnanamurthy ${ }^{2)}$ \\ and Alok Bharadwaj' \\ ${ }^{1)}$ Department of Mechanical Engineering, People's Education Society Institute of Technology \\ Banshankari III Stage, Bangalore- 560085, India \\ ${ }^{2)}$ Department of Mechanical Engineering, Rashtriya Vidyalaya College of Engineering \\ Mysore Road, Bangalore- 560059, India \\ *Corresponding author: csr_gce@yahoo.co.in
}

( Manuscript received 14 July 2014; accepted 15 November 2014; published 15 February 2015 )

\begin{abstract}
Today, in the world of materials the focus is on the development of metal matrix composites (MMC's), particularly aluminium based composites due to its widespread applications in aerospace and automobile industries. To develop light weight MMC's, carbon fibres in both continuous and dis-continuous forms are used as reinforcements. The processing and characterization of mechanical and adhesive wear behaviour of various composites are widely practiced by various researchers around the world. However, solid erosion wear of continuous carbon fibre reinforced MMC's has not yet been reported. In the light of the above, the present work focuses on characteristics of erosive behaviour of A16061-carbon fibre rods composites developed by casting route. Carbon fibre rods of $4 \mathrm{~mm}$ and $6 \mathrm{~mm}$ diameters were surface sensitized to achieve electroless nickel coating followed by copper electroplating on the nickel coated rods and were used as the reinforcements to develop the composites. An air jet erosion rig made according to ASTM G76 standard configuration was used to conduct the tests. The effect of carbon fibre reinforcement, test duration and angle of impingement of the erodent on the erosion wear behaviour of the developed will be discussed at length.
\end{abstract}

Keywords: air jet erosion, A16061, carbon fibre, metal matrix composites

\section{Introduction}

The metal matrix composites are emerging as the most versatile materials for advanced structural, automotive, aviation, aerospace, marine and defense applications. Metal matrix composites consists of metal matrix and reinforcements in the form of viscous, particulate or fibres [1]. They can be tailored to obtain superior properties such as high structural efficiency, excellent wear resistance, attractive thermal and electrical characteristics [2].

Currently MMC's are being explored as the candidate materials for components subjected to hard solid particle erosion. Meager information is available as regards the assessment of solid particle erosion wear of MMC's. Researchers have reported on erosive wear behaviour of polymer based composites [3,4]. Decrease in the angle of impact from $90^{\circ}$ to $20^{\circ}$ has resulted in significant increase in erosive wear loss and ductility [5]. The weight loss of the target material subjected to sand particle erosion tests is directly proportional to kinetic energy and is inversely to the hardness of the target material [6]. Carbon fibers are reported to have very high strength and modulus coupled with excelent lubricity and wear resistance [7]. Owing to these benefits it has been extensively used as reinforcements in discontinous form to develop metal matrix composites with imporoved toughness and tribological properties with reduced friction and wear [8-11].

However, several challenges needs to be addressed such as 1) Carbon fiberstend to get oxidized at temperatures as low as $300^{\circ} \mathrm{C}$ which deteriorates the load carrying capability of the carbon fiber. 2) Poorwettability between carbon fiber and the metallic matrices resulting in poor interfacial bond. 3) Formation of brittle metallic carbides phases [12]. In recent years, these issues are addressed by developing thin adherent electroless metallic coating eithernickel or copper on carbon fibers [13]. Rams et al have demonstrated the effectiveness of nickel coating on short carbon fibers indeveloping high quality A16061 short carbon fiber composites [14]. Sanchez et al have developed aluminium alloy nickel coatedcarbon fiber reinforced composites successfully by centrifugal infiltration [15]. Long Xia et al have used copper coating on carbonfibers developed by electroplating as reinforcement to manufacture copper based composites [7]. Electroless method provides verythin and adherent coatings which are susceptible to damages, while electroplating technique provides a 
dense coating which offersthe carbon fibers higher extent of protection from reaction with metallic matrices during the processing of metal matrixcomposites. Further very less information is available on the combined methods of elctroless and electroplating of metallic coating on carbon fibres although they are interesting and highly effective in offering additional protection to carbon fibres as regards the deterioration of their mechanical properties.

In the light of the above, this work focuses on novel processing of MMC's and assessing its erosive wear behaviour.

\section{Experimental procedure}

Al6061, the most accepted aerospace alloy was chosen as the base alloy (matrix). Al6061 in the form of ingots was used as the matrix alloy (procured from Fen Fee Metallurgicals, Bangalore, India) and its composition is reported in Table 1.

Carbon fibre rods of $6 \mathrm{~mm}$ and $4 \mathrm{~mm}$ diameter was supplied by M/s RC Dhamaka, Bangalore, India, was used as reinforcement within the Al6061 base alloy to fabricate the composites. The diameter of each carbon fibre in the rod was $5 \mu \mathrm{m}$ and these carbon fibre rods were subjected to an electroless nickel coating as reported in our earlier works after proper pre-treatment and sensitization [16]. The electroless nickel coated carbon rods were then coated with copper using conventional copper electroplating bath, with its composition maintained as per standards reported in literature [17].

Copper plated carbon fibre rods were placed in the form concentric circular arrays in the metallic die of inside diameter $80 \mathrm{~mm}$ and height $240 \mathrm{~mm}$ as shown in Fig. 1. To anchor the carbon rods to be in upright position, circular plate of about $5 \mathrm{~mm}$ thickness with holes corresponding to the diameter of the carbon fibre rods was placed at the bottom of the die. Completely degassed aluminium 6061 alloy melt was poured at a temperature of $700^{\circ} \mathrm{C}$ into the preheated metallic moulds (heated to $250^{\circ} \mathrm{C}$ ) containing the array of copper plated carbon rods.

The cast composite casting billets were cut into rectangular sections (of dimensions $50 \mathrm{~mm} \times 25 \mathrm{~mm} \times$ $10 \mathrm{~mm}$ ) and these were subjected to CNC milling and cutting machining to prepare samples for ait jet erosive wear tests. For the air jet erosive wear studies, test samples with two carbon fibre rods symmetrical about the centre line of the rectangular section were prepared.

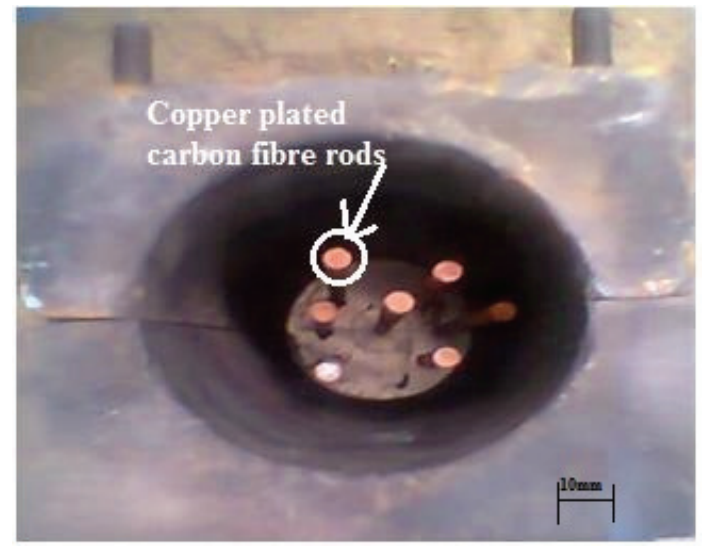

Fig. 1 Photograph of the fixture used to fabricate Al6061- $\mathrm{C}_{\mathrm{f}}$ rod composite $(6 \mathrm{~mm})$

Along with the fabrication of the composites, rectangular samples of the Al6061 base alloy was also fabricated to compare the test results of the composites with that of the base alloy and to study the change in their behavioural characteristics. The developed composite samples and the samples of the base alloy were subjected to dry air jet erosion wear test.

An air jet erosion test machine was used to assess the erosive wear behaviour (M/s Magnum Engineers, Bangalore), which is according to ASTM G-76 standards. Rectangular specimens (both alloy and composites) of dimensions $50 \mathrm{~mm} \times 25 \mathrm{~mm} \times 10$ mmwere used as test samples. Table 2 reports the test conditions adopted during the air jet erosion studies.

The surfaces of the specimens were metallographically polished using emery paper of various grain sizes and flattened so as to distinguish the eroded areas prominently. This was followed by cleaning of the test surface of the specimen with acetone to remove the presence of dust and other foreign particles on the surface that would hinder the outcomes of the erosive wear test. The test specimens were weighed using an electronic micro-balance of accuracy $0.1 \mathrm{mg}$ to note the initial weight of the samples before the test. The test was conducted at room temperature with variation in standoff distance between nozzle and test surface of the specimen, angle of impact of the jet on the test surface and time duration for which the specimens were subjected to erosive wear testing.

The test is performed by propelling a stream of abrasive particulate gas through a small nozzle of

Table 1 Chemical composition of A16061 alloy

\begin{tabular}{|l|l|l|l|l|l|l|l|l|l|}
\hline Elements & $\mathrm{Si}$ & $\mathrm{Fe}$ & $\mathrm{Cu}$ & $\mathrm{Mn}$ & $\mathrm{Mg}$ & $\mathrm{Cr}$ & $\mathrm{Ti}$ & $\mathrm{Zn}$ & $\mathrm{Al}$ \\
\hline Percentage (\%) & $0.4-$ & 0.70 & $0.15-$ & 0.15 & $0.8-$ & $0.04-$ & 0.15 & 0.25 & \\
& 0.80 & $\max$ & 0.40 & $\max$ & 1.2 & 0.35 & $\max$ & $\max$ & \\
& & & & & & & & & \\
\hline
\end{tabular}


Table 2 Air Jet Erosion Test Conditions

\begin{tabular}{|c|c|c|}
\hline SI & \multicolumn{2}{|c|}{ Test parameters } \\
\hline 1 & Erodent material & Silica sand \\
\hline 2 & Erodent size $[\mu \mathrm{m}]$ & 312 \\
\hline 3 & Particle velocity [m/s] & 30 \\
\hline 4 & Erodent feed rate $[\mathrm{g} / \mathrm{m}]$ & 2 \\
\hline 5 & Impact angle [degrees] & $90,60,45$ and 30 \\
\hline 6 & Test temperature & Room temperature \\
\hline 7 & Test time [minutes] & $5,10,15,20$ \\
\hline 8 & Sample size [mm] & $50 \times 25 \times 10$ \\
\hline 9 & Nozzle inner diameter [mm] & 1.5 \\
\hline 10 & Standoff distance [mm] & $20,30,40,50$ \\
\hline 11 & System pressure [bar] & 1.4 \\
\hline
\end{tabular}

known orifice diameter toward the test sample. Repeated tests were conducted on various samples by varying the parameters as mentioned above. After the tests were conducted, the specimens were again cleaned with acetone before weighing them so as to remove the sand particles clinging on to the eroded surface of the test specimen, which might reduce the accuracy of the measurement of the weight loss of the specimen.

Material loss, in this case, is achieved via the impingement of small abrasive particles upon the test surface. The specimens were weighed before and after testing to find out the weight loss.

\section{Results and discussion}

\subsection{Microhardness}

The enhancement in micro-hardness is $20 \%$ and $27 \%$ for $4 \mathrm{~mm} \mathrm{C}_{\mathrm{f}}$ rod and $6 \mathrm{~mm} \mathrm{C}_{\mathrm{f}}$ rod composites respectively. This can be attributed to the reduction in the grain size. Smaller the grain size greater will be the resistance to dislocation mobility. This restricted mobility of the dislocations which are generated due to thermal miss-match between carbon fibre rod and between copper and aluminium alloy is responsible in retarding the plastic deformation. Hui $\mathrm{Lu}$ et al, have reported enhancement in the dislocation density due to the thermal mis-match between the reinforcement and the matrix

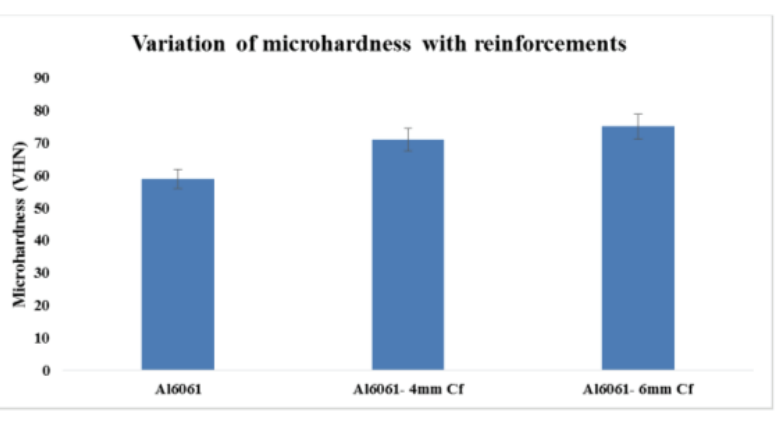

Fig. 2 Variation of microhardness Al6061 base alloy and Al6061-Cf rod composites (6 $\mathrm{mm}$ and 4 $\mathrm{mm} \mathrm{C}_{\mathrm{f}}$ rods)

[18]. The reported values of co-efficient of thermal expansion (CTE) of Al6061 alloy and copper are $23.6 \times$ $10^{-6} / \mathrm{K}$ and $16.5 \times 10^{-6} / \mathrm{K}$ respectively [19]. Carbon fibre possesses CTE values of $5.5-8.4 \times 10^{-6} / \mathrm{K}$ and -0.5 to $1.3 \times 10^{-6} / \mathrm{K}$ along transverse and longitudinal directions respectively [20]. Figure 2 shows the variation of microhardness in Al6061 base alloy and Al6061- $\mathrm{C}_{\mathrm{f}}$ rod composites (6 $\mathrm{mm}$ and $4 \mathrm{~mm} \mathrm{C}_{\mathrm{f}}$ rods).

\subsection{Erosion weight loss}

3.2.1 Effect of carbon rod reinforcement

Figure 3 shows the influence of Carbon fibre $\left(C_{f}\right)$ rod reinforcement on the weight loss due to erosion of Al6061- $\mathrm{C}_{\mathrm{f}}$ rod composite. In all cases studied A16061- $\mathrm{C}_{\mathrm{f}}$ rod composites do exhibit higher wear resistance when compared with Al6061 base alloy.

The improved erosive wear resistance of Al6061- $\mathrm{C}_{\mathrm{f}}$ rod composites is attributed to the higher hardness of composites when compared with the matrix alloy. Higher the hardness of the materials lesser will be the extent of surface damage and plastic deformation which in turn significantly the affects the material loss during erosion [21]. Erosion is a phenomenon where the material is removed due to impact collisions of hard erodent particles. The presence of second phase in MMCs in particular the fibres do play a major role in minimising surface damage during erosion resulting in significantly low material loss [22]. This fact is well established by

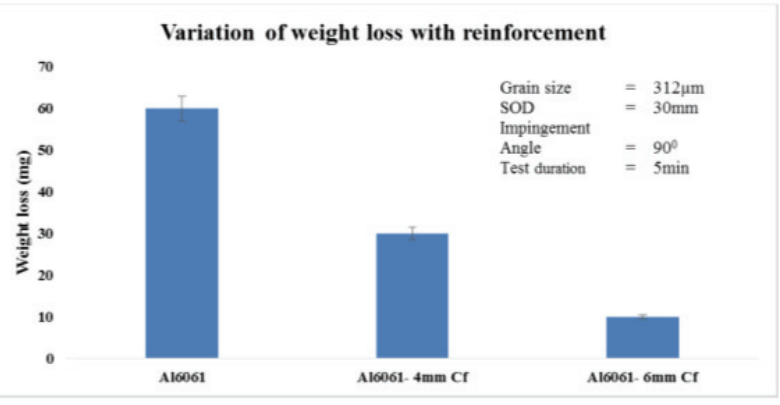

Fig. 3 Variation of weight loss of Al6061 base alloy and Al6061- $\mathrm{C}_{\mathrm{f}}$ rod composites $(6 \mathrm{~mm}$ and 4 $\mathrm{mm} \mathrm{C}_{\mathrm{f}}$ rods) 
SEM studies as discussed below.

The unreinforced matrix alloy Al 6061 do exhibits extensive surface damage as shown in Fig. 4(a). The cracks are continuous, wide and deep indicating high degree of plastic deformation during erosion process. On the other hand carbon fibre reinforced composites do exhibit scratches and significantly very low levels of cracking in the matrix portion of the composite as shown in Figs. 4(b) and (c).

Further the carbon fibres are not damaged with no pull out of the carbon fibres being observed as shown in SEM of the worn surfaces in the fibre region (Figs. 4(d) and (e)).Carbon fibres having high stiffness and strength are mainly responsible for the surface strengthening in minimising cracking and material removal.

Figure 4 shows the SEM images of eroded surfaces of Al6061 alloy and Al6061- $\mathrm{C}_{\mathrm{f}}$ rod composites $(6 \mathrm{~mm}$ and $4 \mathrm{~mm} \mathrm{C}_{\mathrm{f}}$ rods) at $90^{\circ}$ impingement of $312 \mu \mathrm{m}$ and for 5 minutes and $30 \mathrm{~mm}$ stand of distance.

\subsubsection{Effect of impingement angle}

The variation of weight loss due to solid particle erosion of the matrix alloy and the developed composites with the angle of impingement is shown in Fig. 5. It is observed that an average reduction of $40 \%$ and $70 \%$ weight loss is observed for Al6061-4 mm $\mathrm{C}_{\mathrm{f}}$ and Al6061-6 $\mathrm{mm} \mathrm{C}_{\mathrm{f}}$ respectively when compared with the

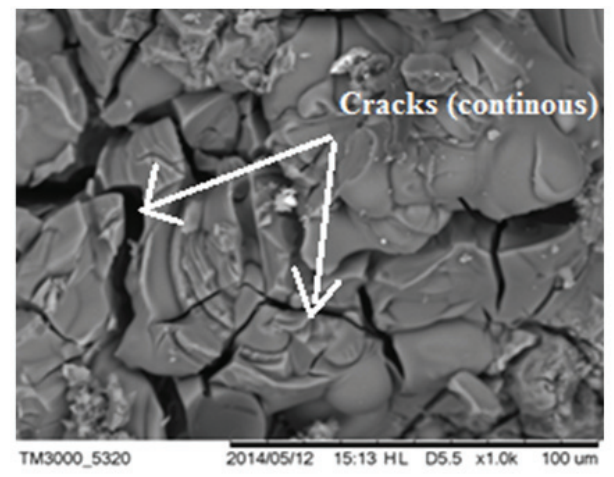

(a)

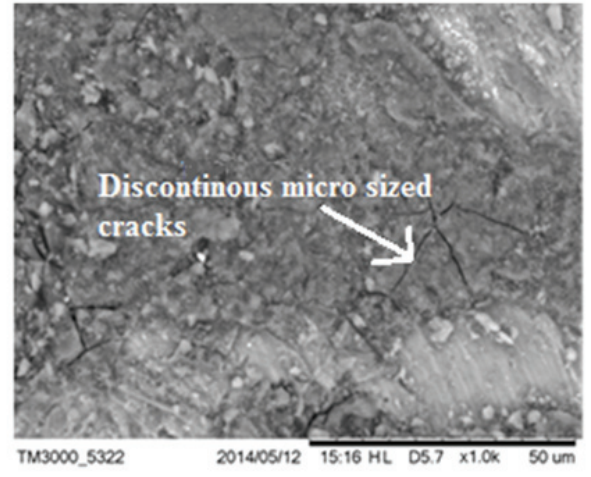

(b)

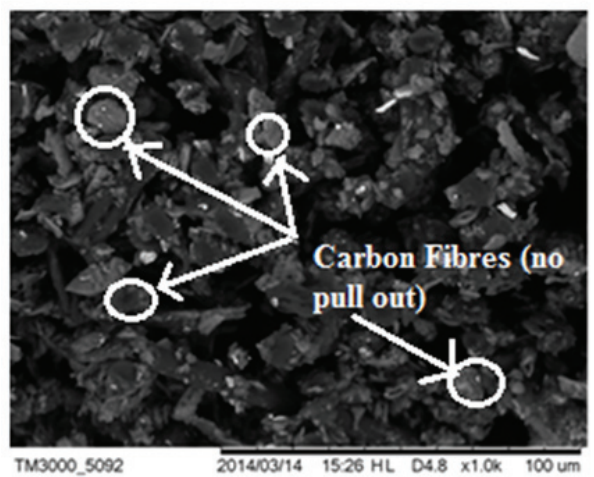

(d)

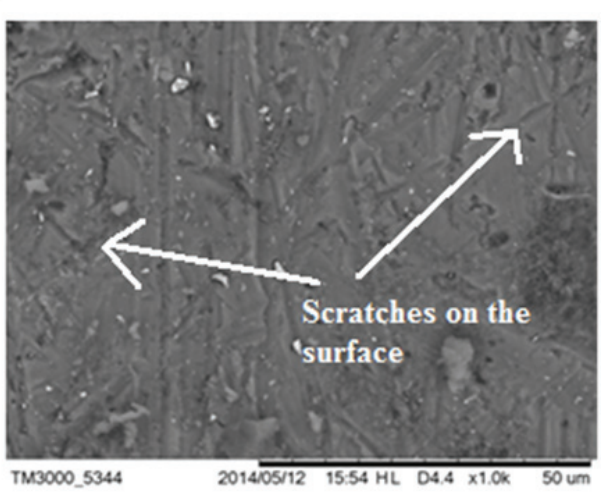

(c)

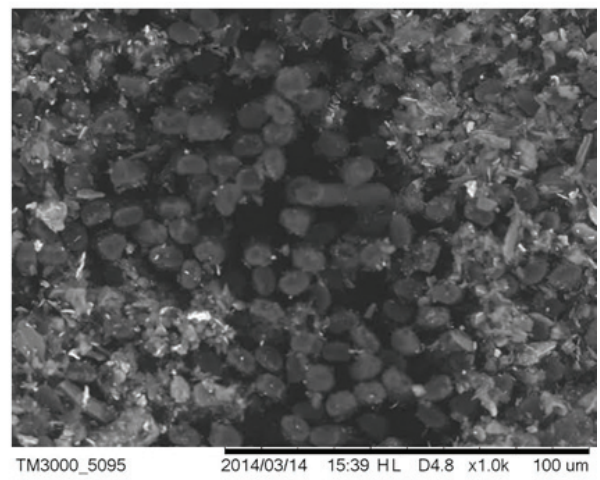

(e)

Fig. 4 (a) The SEM image of Al6061. (b) Al6061-4 mm $\mathrm{C}_{\mathrm{f}}$ composite and (c) Al6061-6 mm $\mathrm{C}_{\mathrm{f}}$ composite in matrix region. (d) Al6061-4 $\mathrm{mm} \mathrm{C}_{\mathrm{f}}$ composite and (e) Al6061-6 $\mathrm{mm} \mathrm{C}_{\mathrm{f}}$ composite in fibre region 


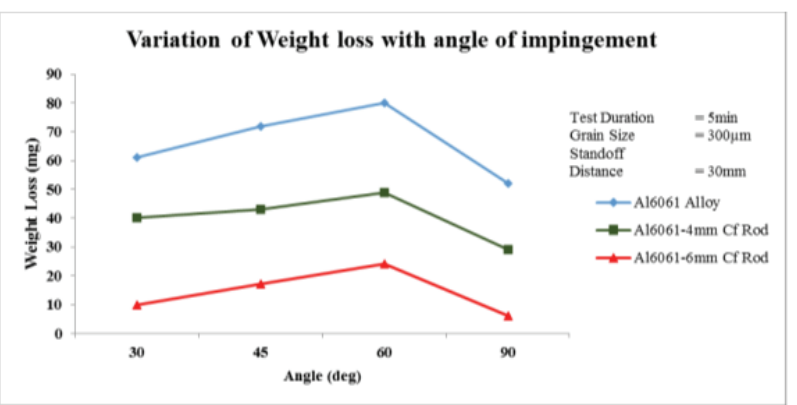

Fig. 5 Variation of weight loss of Al6061 alloy and Al6061- $\mathrm{C}_{\mathrm{f}}$ rod composites $(6 \mathrm{~mm}$ and $4 \mathrm{~mm}$ $\mathrm{C}_{\mathrm{f}}$ rods) for different angles of impingement

matrix alloy for all the studied angle of impacts. This demonstrates that the developed composite possesses excellent erosion wear resistance when compared with the matrix alloy. It is observed that maximum and minimum erosive wear loss for both the matrix alloy and the developed composite occurs at the impact angle of $60^{\circ}$ and $90^{\circ}$ respectively. This is in accordance with the other researchers $[23,24]$. The maximum erosive wear loss can be attributed to the higher contact area between the erodent particle and target leading to the high deformation stresses resulting in severe surface degradation.

\subsubsection{Effect of Standoff Distance (SOD)}

The variation of weight loss due to solid particle erosion of matrix alloy and the developed composites with the standoff distance is shown in the Fig 6. It is observed that the weight loss decreases with an increase in the standoff distance for both the matrix alloy and the composites. An average reduction in weight loss for Al6061-4 mm $\mathrm{C}_{\mathrm{f}}$ and Al6061-6 $\mathrm{mm} \mathrm{C}_{\mathrm{f}}$ composites was found to be $32 \%$ and $50 \%$ respectively when compared with the matrix alloy at all the studied conditions. The reduction in weight loss due to the increase in standoff distance can be attributed to the fact that with an increase in standoff distance, the erodent particles have to travel further more to reach the surface of the specimen. The

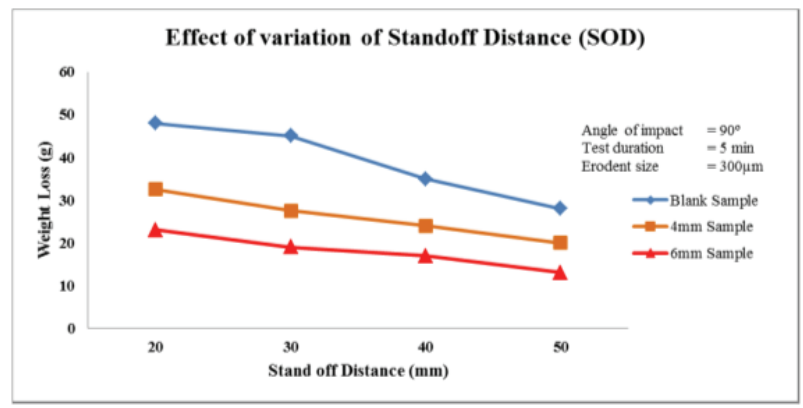

Fig. 6 Variation of weight loss of both Al6061 alloy and Al6061-Cf rod composites (6 $\mathrm{mm}$ and 4 $\mathrm{mm} \mathrm{C}_{\mathrm{f}}$ rods) for different Standoff Distances (SOD) particles will experience air friction along its travel and lose much of its energy before striking the surface [25]. Also as the standoff distance increases, the particles tend to scatter outwards, thus the probability of the erodent striking the surface reduces. Hence, the weight loss decreases with increase in standoff distance. It can be observed that the variation of weight loss with standoff distance is not very significant.

This result is justified by the following SEM images as shown in Fig. 7(a, b and c) which were taken from the samples subjected to the test at different standoff distances (20 mm, $40 \mathrm{~mm}$ and $50 \mathrm{~mm}$ ) for Al6061-4 mm

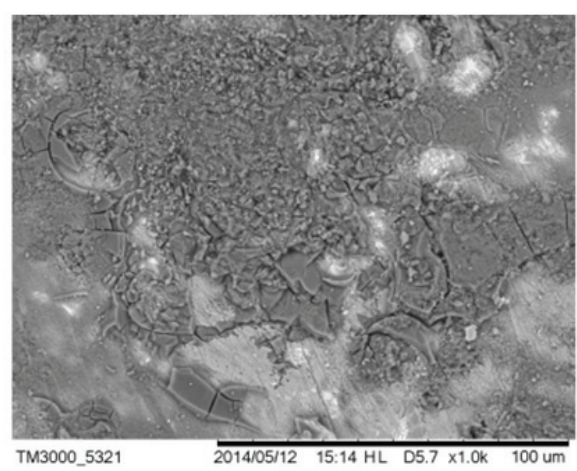

(a) $\mathrm{SOD}=20 \mathrm{~mm}$

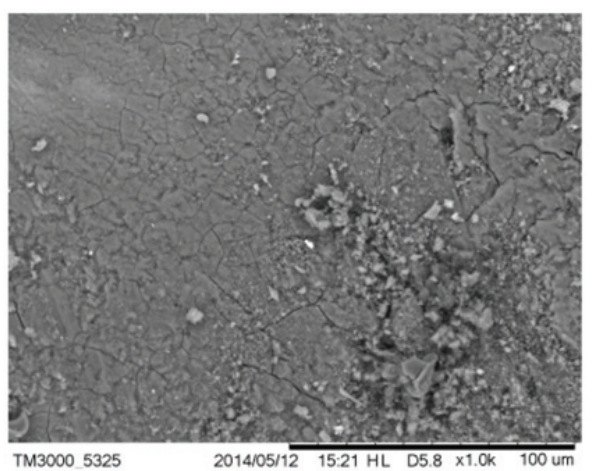

(b) $\mathrm{SOD}=40 \mathrm{~mm}$

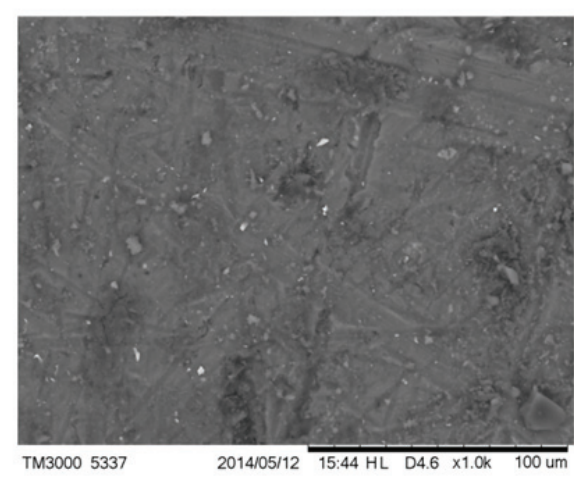

(c) $\mathrm{SOD}=50 \mathrm{~mm}$

Fig. 7 SEM images of worn surfaces of Al661-4 mm $\mathrm{C}_{\mathrm{f}}$ rod composite at different standoff distances 


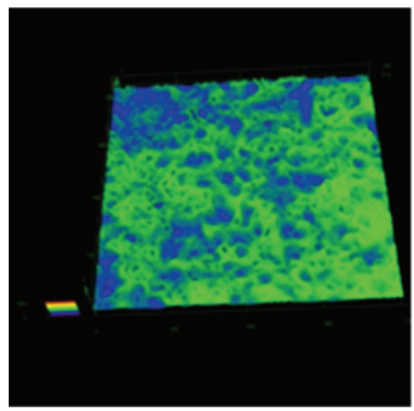

(a) $\mathrm{SOD}=20 \mathrm{~mm}$

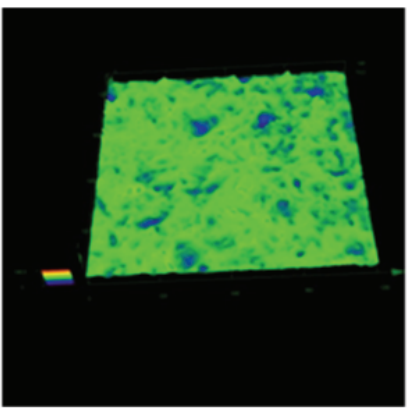

(b) $\mathrm{SOD}=40 \mathrm{~mm}$

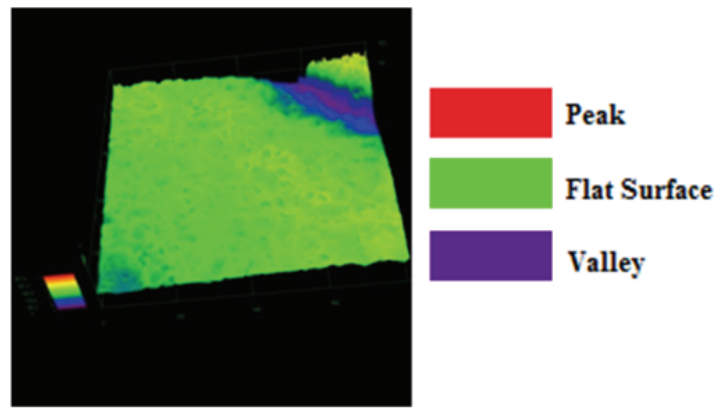

(c) $\mathrm{SOD}=50 \mathrm{~mm}$

Fig. 8 Confocal Images of worn surfaces of Al661-4 mm $\mathrm{C}_{\mathrm{f}}$ rod composite at different standoff distances

\section{$\mathrm{C}_{\mathrm{f}}$ composite.}

In order to strengthen the above statement, the images of the confocal microscope as shown in Fig. 8 (a, b \& c) confirmed that weight loss is minimum at a higher standoff distances.

\subsubsection{Effect of test duration}

Figure 9 shows the variation of weight loss during air jet erosion wear of both Al6061 alloy and Al6061- $\mathrm{C}_{\mathrm{f}}$ rod composites ( $6 \mathrm{~mm}$ and $4 \mathrm{~mm} \mathrm{C}_{\mathrm{f}}$ rods) with varying test durations for $90^{\circ}$ angle of impact. It is observed that erosive weight loss of both Al6061 alloy and Al6061- $\mathrm{C}_{\mathrm{f}}$ rod composites $\left(6 \mathrm{~mm}\right.$ and $4 \mathrm{~mm} \mathrm{C}_{\mathrm{f}}$ rods) increases linearly with increase in test duration. The kinetic energy and the momentum of the erodent particles are transferred to the surface during collision, and this causes material removal from the surface. The material characteristics and process parameters play a vital role in erosive wear mechanisms.

SEM images of the composite were analysed during the course of test at regular time intervals of 5 minutes. The SEM images of the eroded sample at $90^{\circ}$ angle of impingement and $30 \mathrm{~mm}$ standoff distance for varying test durations are as shown. The surface morphology of the eroded surface revealed the following conclusions.

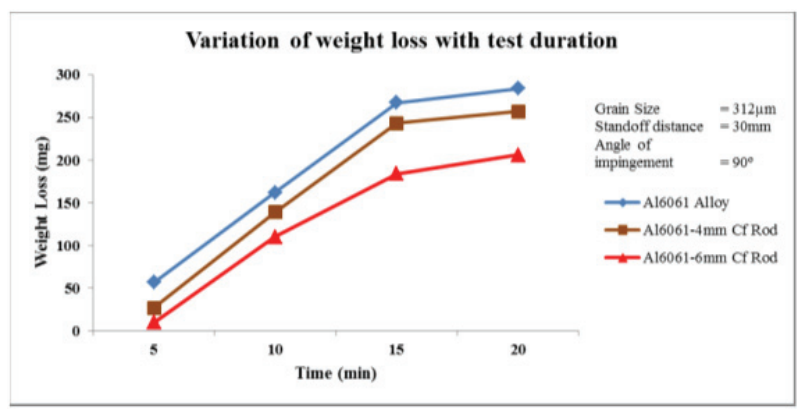

Fig. 9 Variation of weight loss of Al6061 alloy and Al6061- $\mathrm{C}_{\mathrm{f}}$ rod composites $\left(6 \mathrm{~mm}\right.$ and $4 \mathrm{~mm} \mathrm{C}_{\mathrm{f}}$ rods) with different test duration
Initially the composite did not show much erosion features for the first five minutes of erodent impingement. After ten minutes of erosion, grooves were observed in some parts of the composite surface but still major portion of the surface remained flat (Fig. 10(a)). After 15 minutes of erosion time the grooves started growing (Fig. $10(\mathrm{~b})$ ), then as the erosion continued at the end of 20 minutes massive cavitation and cracking of grains is observed (Fig. 10(c)). However, it is observed that wear rates of both the matrix alloy and the composites increase with the increase in test duration. This can be attributed to the brittle type of fracture mechanism operating.

\section{Conclusions}

Al6061 -carbon fibre rod composites have been successfully developed by plating the carbon fibre rods with nickel and copper and reinforcing them with base metal matrix. There is a significant reduction in air jet erosive wear loss of the carbon fibre composites with an increase in the weight percent of $\mathrm{C}_{\mathrm{f}}$ rod reinforcement under all the studied experimental conditions. Increase in the angle of impingement has resulted in the increase in erosion weight loss up to $60^{\circ}$. Thereon, brittle fracture dominates and results in decrease in weight loss till $90^{\circ}$. The $\mathrm{Al} 6061-\mathrm{C}_{\mathrm{f}}$ rod composites possess better erosive wear resistance when compared with Al6061 alloy under identical test conditions. The three dimensional microscopic and SEM studies on surface of air jet eroded metal matrix composites has contributed significantly in enunciating the erosive wear mechanism.

\section{Acknowledgements}

The authors gratefully acknowledge the cooperation and support extended by Prof. D. Jawahar, CEO, PES Institutions and Dr. K. N. B. Murthy, Principal, PES Institute of Technology, Bangalore in carrying out this work. 


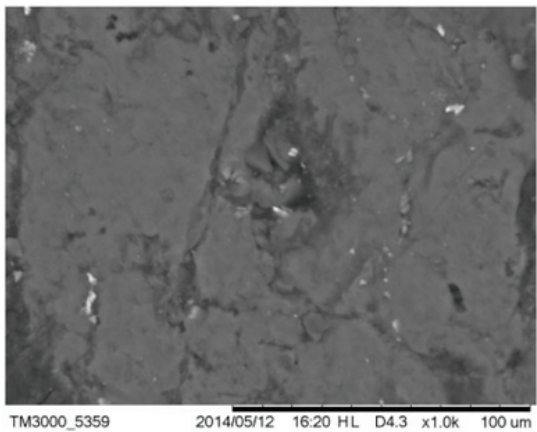

(a) Duration $=10 \mathrm{~min}$

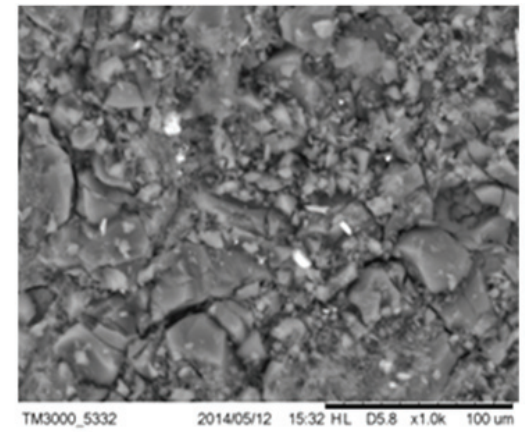

(b) Duration $=15 \mathrm{~min}$

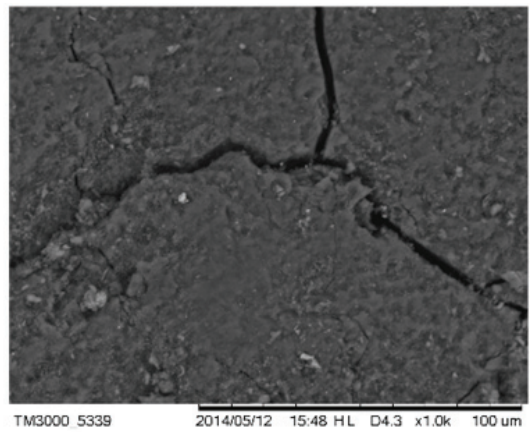

(c) Duration $=20 \mathrm{~min}$

Fig. 10 SEM images of worn surfaces of Al661-4 $\mathrm{mm} \mathrm{C}_{\mathrm{f}}$ rod composite at different test durations

\section{References}

[1] Ramesh, C. S., "Engineering Materials," Spectrum Publishers, Bangalore, 1995, 65.

[2] Miracle, D. B., "Metal Matrix Composites - From Science to Technological Significance," Composites Science and Technology, 65, 15-16, 2005, 2526-2540.

[3] Sinmazçelik, T., Fiden, S. and Günay, V., "Residual Mechanical Properties of Carbon/ Polyphenylenesulphide Composites after Solid Particle Erosion," Materials \& Design, 29, 7, 2008, 1419-1426.

[4] Mahapatra, S. S. and Patnaik, A., "Study on Mechanical and Erosion Wear Behavior of Hybrid Composites using Taguchi Experimental Design," Materials and Design, 30, 8, 2009, 2791-2801.

[5] Mac Millin, B. E., Roll, C. D. and Funkenbusch, P., "Erosion and Surface Structure Development of Metal-Diamond Particulate Composites," Wear, 269, 11-12, 2010, 875-883.

[6] Wood, R. J. K. and Speyer, A. J., "Erosion-Corrosion of Candidate HVOF Aluminium-Based Marine Coatings," Wear, 256, 5, 2004, 545-556.

[7] Long, X., Jia, B., Zeng, J. and Xu, J., "Wear and Mechanical Properties of Carbon Fiber Reinforced Copper Alloy Composites," Materials Characterization, 60, 5, 2009, 363-369.

[8] Naji, H., Zebarjad, S. M. and Sajjadi, S. A., "The Effects of Volume Percent and Aspect Ratio of Carbon Fiber on Fracture Toughness of Reinforced Aluminum Matrix Composites," Materials Science and Engineering A, 486, 1-2, 2008, 413-420.

[9] Liu, L., Li., W., Tang, Y., Shen., B. and Hu, W., "Friction and Wear Properties of Short Carbon Fiber Reinforced Aluminum Matrix Composites," Wear, 266, 7-8, 2009, 733-738.

[10] Zeng, J., Xu, J., Hua. W., Xia, L., Deng, X., Wang, S., Tao, P., Ma, X., Yao, J., Jiang, C. and Lin, L.,
"Wear Performance of the Lead Free Tin Bronze Matrix Composite Reinforced by Short Carbon Fibers," Applied Surface Science, 255, 13-14, 2009, 6647-6651.

[11] Ramesh, C. S., Keshavamurthy, R., Pramod, S. and Praveennath, G. K., "Abrasive Wear Behavior of $\mathrm{Ni}-\mathrm{P}$ Coated $\mathrm{Si}_{3} \mathrm{~N}_{4}$ Reinforced Al6061 Composites," Journal of Materials Processing Technology, 211, 8, 2011, 1423-1431.

[12] Steffens, H. -D., Reznik, B., Kruzhanov, V. and Dudzinski, W., "Carbide Formation in Aluminium-Carbon Fibre-Reinforced Composites," Journal of Materials Science, 32, 20, 1997, 5413-5417.

[13] Ramesh, C. S. and Prasad, T. B., "Dry Sliding Friction and Wear Behaviour of Hypereutectic Al-Si-Carbon Fibre Metal Matrix Composite," Tribology-Materials, Surfaces \& interfaces, 1, 4, 2007, 197-202.

[14] Rams, J., Ureña, A., Escalera, M. D. and Sánchez, M., "Electroless Nickel Coated Short Carbon Fibers in Aluminium Matrix Composites," Composites, Part A, 38, 2, 2007, 566-575.

[15] Sánchez, M., Rams, J. and Ureña, A., "Fabrication of Aluminium Composites Reinforced with Carbon Fibres by a Centrifugal infiltration Process," Composites, Part A, 41, 11, 2010, 1605-1611.

[16] Ramesh, C. S., Adarsha, H., Pramod, S. and Khan, Z., "Tribological Characteristics of Innovative Al6061-Carbon Fiber Rod Metal Matrix Composites," Materials \& Design, 50, 2013, 597-605.

[17] Schlesinger, M., "Modern Electroplating," John Wiley and Sons, New Jersey, 2010, 736.

[18] Hui, L., Xianping, W., Tao, Z., Zhijun, C. and Quianfeng, F., "Design, Fabrication and Properties of High Damping Metal Matrix Composites- a Review," Materials, 2, 3, 2009, 958-977.

[19] Chou, T. W., Kelly, A. and Okura, A., "Fibre-Reinforced Metal-Matrix Composites," Composites, 16, 3, 1985, 187-206. 
[20] Chawla, K. K., "Composite Material Science and Engineering," 2nd Edition, Springer, New York, 1998, 33.

[21] Ramesh, C. S., Seshadri, S. K. and Iyer, K. J. L., "A Survey of Aspects of Wear of Metals," Indian Journal of Technology, 29, 4, 1991, 179-185.

[22] Khoddamzadeh, A., Liu, R., Liang, M. and Yang, Q., "Novel Wear Resistant Materials-Carbon Fiber Reinforced Low-Carbon Stellite Alloy Composites," Composites Part A, Applied Science \& Manufacturing, 43, 3, 2011, 344-352.

[23] MacMillin, B., E., Roll, C., D. and Funkenbusch, P., "Erosion and Surface Structure Development of
Metal-Diamond Particulate Composites," Wear, 269, 11-12, 2010, 875-883.

[24] Wood, R. J. K. and. Speyer, A. J., "Erosion-Corrosion of Candidate HVOF Aluminium-Based Marine Coatings," Wear, 256, 5, 2004, 545-556.

[25] Mishra, S. C., Swayam, P., Mishra, A. K., Panigrahi, S. C. and Samal, B. P., "Studies on Erosion Wear Behaviour of Aluminium-3 Magnesium-10 Silicon Carbide Composite," Journal of Materials and Metallurgical Engineering, 3, 3, 2003, 39-50. 